\title{
Classification of cesarean section through Robson criteria: an emerging concept to audit the increasing cesarean section rate
}

\author{
Anita Kant, Shweta Mendiratta*
}

Department of Obstetrics and Gynecology, Asian Institute of Medical Sciences, Faridabad, Haryana, India

Received: 08 September 2018

Accepted: 11 October 2018

\section{*Correspondence:}

Dr. Shweta Mendiratta,

E-mail: shwetsmendiratta@gmail.com

Copyright: (C) the author(s), publisher and licensee Medip Academy. This is an open-access article distributed under the terms of the Creative Commons Attribution Non-Commercial License, which permits unrestricted non-commercial use, distribution, and reproduction in any medium, provided the original work is properly cited.

\begin{abstract}
Background: There has been an increase in rate of cesarean section over last five decades. This is a matter of international public health concern as it increases the cesarean section related maternal morbidity. The aim of the present study was to audit the increasing rate of caesarean section.

Methods: In the present study, all cases delivered by cesarean section during the period of six months were recorded and classified according to Robson's 10 group classification system. This was an attempt to see which clinically relevant groups contributed most to the cesarean deliveries.

Results: There was a trend of increased percentage of cesarean section in group 5 and 2 respectively in present study. Increasingly sedentary lifestyle and poor tolerance to pain are adding to cesarean delivery on maternal request.

Conclusions: We should judiciously make use of vaginal birth after cesarean section but not at the cost of maternal or fetal health. Standardization of indication of cesarean deliveries, regular audits and definite protocols in hospital will aid in curbing the rate of cesarean deliveries in hospitals.
\end{abstract}

Keywords: Cesarean section, Robson's classification

\section{INTRODUCTION}

There has been an increase in rate of cesarean section over last five decades. It has increased from a rate of $5 \%$ in 1940 s and 1950 s to $15 \%$ in 1970 and 1980 s. However there has been a dramatic increase in the cesarean section rate globally, even beyond $30 \%$ in some areas.

As advised by WHO guidelines and US Healthy initiative 2000, the cesarean section rate should not be beyond 15 $\% .^{1}$ However, there was an upward trend of cesarean section rate as there were no reliable and internationally standardised data enabling a global comparison for the indications of cesarean sections.

The increasing rate of cesarean section is a matter of international public health concern as it increases the cesarean section related maternal morbidity., ${ }^{2,3,4}$ Hence arose the need of standardization of classification of cesarean section through Robson criteria within the healthcare facilities as proposed by MS Robson in the year 2001. The 10 group Robson classification of caesarean section has been appreciated by WHO in 2014 and FIGO in 2016.,5 According to WHO, Robson classification will aid in optimisation of the cesarean section use, assessment of the strategies aimed to decrease the cesarean section rate and thus improve the clinical practises and quality of care in various health care facilities. So, we made an attempt to classify the caesarean section based on this system to address the cause of rising caesarean section in our scenario. The objectives of the study were:

- To classify the cesarean section according to their causes.

- To identify and audit the rising causes of cesarean section in our scenario.

- To standardise the indications of cesarean section. 
Table 1: Robson's classification of cesarean section.,

\begin{tabular}{|c|c|}
\hline Groups & Clinical characteristics \\
\hline 1 & $\begin{array}{l}\text { Nulliparous, singleton, cephalic, } \geq 37 \text { weeks, } \\
\text { spontaneous labor }\end{array}$ \\
\hline 2 & $\begin{array}{l}\text { Nulliparous, singleton, cephalic, } \geq 37 \text { weeks, } \\
\text { induced labor or cesarean section before } \\
\text { labor }\end{array}$ \\
\hline 3 & $\begin{array}{l}\text { Multiparous without previous cesarean } \\
\text { section, singleton, cephalic, } \geq 37 \text { weeks, } \\
\text { spontaneous labor }\end{array}$ \\
\hline 4 & $\begin{array}{l}\text { Multiparous without previous cesarean } \\
\text { section, singleton, cephalic, } \geq 37 \text { weeks, } \\
\text { induced labor or caesarean section before } \\
\text { labor }\end{array}$ \\
\hline 5 & $\begin{array}{l}\text { Multiparous with prior cesarean section, } \\
\text { singleton, cephalic, } \geq 37 \text { weeks }\end{array}$ \\
\hline 6 & All nulliparous breeches \\
\hline 7 & $\begin{array}{l}\text { All multiparous breeches (including } \\
\text { previous cesarean section) }\end{array}$ \\
\hline 8 & $\begin{array}{l}\text { All multiple pregnancies (including } \\
\text { previous cesarean section) }\end{array}$ \\
\hline 9 & $\begin{array}{l}\text { All pregnancies with transverse or oblique } \\
\text { lie (including those previous cesarean } \\
\text { section) }\end{array}$ \\
\hline 10 & $\begin{array}{l}\text { Singleton, cephalic, } \leq 36 \text { weeks (including } \\
\text { previous cesarean section) }\end{array}$ \\
\hline
\end{tabular}

\section{METHODS}

The present study was carried out retrospectively over a period of six months from October'17 to March'18 in the department of Obstetrics and Gynecology, Asian Institute of Medical Sciences, Faridabad, India. All data was retrieved and entered in a preformed structured performa.

\section{Inclusion criteria}

- Patients delivered by caesarean section during the given period (October'17 to March'18) were recorded and classified according to Robson's 10 group classification system as given in Table 1.

The parameters considered were according to the classification system

- $\quad$ Parity (with/ without previous CS);

- Gestational age (>37/<36 weeks),

- Fetal presentation (cephalic/ breech / abnormal lie)

- Number of fetuses (singleton/ multiple)

- Onset of labour (spontaneous/ induced / prelabour CS). (Table I)

\section{Exclusion criteria}

- Term normal or instrumental vaginally delivered patients.
- Preterm normal or instrumental vaginally delivered patients.

Data collected was analysed using simple statistical measures like percentage and proportion. Descriptive statistical analysis was done. The study was conducted after taking approval from institutional ethical committee.

\section{RESULTS}

The total number of deliveries over this period in the hospital was 531 out of which no. of cesarean section were 286 which denotes percentage of cesarean section was 53.86 percent.

There were 30 cesarean sections on maternal request which denotes about 10.4 percent. 35 cases among the group of cesarean section had intrahepatic cholestasis of pregnancy, requiring induction of labour that denotes 12.2 percent.

When the data was analyzed as shown in table II; the maximum contribution of cesarean was through Robson's group 2 that is nulliparous, singleton, cephalic, $\geq 37$ weeks, induced labor or cesarean section before labor.

There was a trend of increased percentage of cesarean section in group 5 (multiparous with prior cesarean section, singleton, cephalic, $\geq 37$ weeks) and 2 (nulliparous, singleton, cephalic, $\geq 37$ weeks, induced labor or cesarean section before labor) which was 36 and 36.71 percent respectively. Induction of labour increased the chances of caesarean section.

The caesarean section rate in group 1 (nulliparous, singleton, cephalic, $\geq 37$ weeks, spontaneous labor) (18.4\%) and 3 (multiparous without previous cesarean section, singleton, cephalic, $\geq 37$ weeks, spontaneous labor) $(5.76 \%)$ was less as they came in spontaneous labour as compared with group 2 ( nulliparous, singleton, cephalic, $\geq 37$ weeks, induced labor or cesarean section before labor) (69.53\%) and 4 ( multiparous without previous cesarean section, singleton, cephalic, $\geq 37$ weeks, induced labor or caesarean section before labor) $(22.58 \%)$ respectively where the labour was induced (Percent values given in Table II). There was an increased contribution of cesarean section by group 5 (multiparous with prior cesarean section, singleton, cephalic, $\geq 37$ weeks) and 2 (nulliparous, singleton, cephalic, $\geq 37$ weeks, induced labor or cesarean section before labor) which was 36 and 36.71 percent respectively as seen in present study. The rate of caesarean section increases in patients with previous caesarean section (group 5). Although these patients were offered trial of labour, yet the rate of refusal by these patients for trial of labour was high. 
Table 2: Cesarean section rate and contribution made by each group.

\begin{tabular}{|llllll|}
\hline $\begin{array}{l}\text { Robson's } \\
\text { criteria }\end{array}$ & $\begin{array}{l}\text { Total no. of } \\
\text { deliveries in each } \\
\text { group }\end{array}$ & $\begin{array}{l}\text { Total no of } \\
\text { cesarean in each } \\
\text { group }\end{array}$ & $\begin{array}{l}\text { Relative size of } \\
\text { group }(\%)\end{array}$ & $\begin{array}{l}\text { Contribution made } \\
\text { rate percent }\end{array}$ & $\begin{array}{l}\text { Cesarean section rate } \\
\text { by each group to total } \\
\text { (\%) }\end{array}$ \\
\hline 1 & 114 & 21 & 21.47 & 18.4 & 7.34 \\
\hline 2 & 151 & 105 & 28.44 & 69.53 & 36.71 \\
\hline 3 & 52 & 3 & 9.79 & 5.76 & 1.04 \\
\hline 4 & 31 & 7 & 5.83 & 22.58 & 2.4 \\
\hline 5 & 109 & 103 & 20.53 & 94.49 & 36 \\
\hline 6 & 6 & 6 & 1.12 & 100 & 2.09 \\
\hline 7 & 2 & 2 & 0.38 & 100 & 0.6 \\
\hline 9 & 9 & 9 & 1.7 & 100 & 3.14 \\
\hline 10 & 55 & 2 & 0.38 & 100 & 0.6 \\
\hline
\end{tabular}

\section{DISCUSSION}

Standardisation and classification of cesarean deliveries was done for the first time in our department according to the Robson's criteria. This was an attempt to see which clinically relevant groups contributed most to the cesarean deliveries. As we observed in present study, the rate of cesarean section in our hospital $(53.86 \%)$ is quite higher than what has been considered by WHO (15\%). The cesarean section rate depicted in year 2013-2014 in India was $16.4 \% .^{7}$ This rose to $18 \%$ in $2015-16$ when a health survey was conducted by Nation Family Health Survey. The average cesarean rate in Asian countries (27.3\%) was much lower when compared with USA $(31.1 \%)^{2,8}$

Vogel et al analysed the contributions of specific groups through Robson's 10 group classification system in 2 WHO multi- country surveys and concluded the proportion of women with previous caesarean section has increased along with the caesarean section rate in these women as we see in present study. ${ }^{9}$ Similarly, the use of induction and pre- labour caesarean caesarean section and caesarean section after induction in multiparous has also increased according to them. In present study also group 2 and 4 had an increased caesarean section rate when compared with 1 and 3 respectively.

Hence, the need of the hour is to firstly limit induction of labour. It should be strictly evidence based. Secondly, we should critically evaluate on daily basis the indication of primary caesarean section. This will not only decrease the caesarean section in nulliparous but will also eventually decrease caesarean section in multiparous with previous caesarean section. The hospital where this study was conducted was a tertiary care centre where there is large number of referred high risk cases. There is an increase in trend of cesarean section on maternal request.

Moreover, the number of patients with intrahepatic cholestasis of pregnancy is increasing. So, it is quite difficult to restrict the percentage to an ideal figure and this might not be the figure of the entire state of Haryana. However, we need to reduce the number of cesarean sections in primiparas and make judicious use of vaginal birth after cesarean deliveries but not at the cost of health of mother and baby.

ACOG recently recommended clinical guidelines to restrict the number of cesarean deliveries which are nonmedically indicated and induction of labour before 39 weeks of gestation. ${ }^{10}$ Efforts to reduce such births should include awareness to public, reducing unindicated induction before 39 weeks certain changes and standardization in the departmental policies. Increasingly sedentary lifestyle and poor tolerance to pain are adding to CSMR ratio.

Authors should judiciously make use of vaginal birth after cesarean deliveries but not at the cost of maternal or fetal health. Standardization of indication of cesarean deliveries, regular audits and definite protocols in hospital will aid in curbing the cesarean section rate in hospital. This will definitely aid in decreased maternal morbidity associated with cesarean delivery rates, reduce the hospital stay and in turn improve the economy. At the same time, one should make every effort to provide the cesarean delivery to the woman in clinically indicated need rather than to achieve a specific rate.

\section{ACKNOWLEDGMENTS}

Authors would like to thank the staff of Department of Obstetrics and Gynecology, Asian Institute of Medical Sciences, Faridabad, Haryana for their support during study.

Funding: No funding sources

Conflict of interest: None declared

Ethical approval: The study was approved by the Institutional Ethics Committee 


\section{REFERENCES}

1. WHO Statement on Cesarean Section Rates; WHO/RHR/15.02. Available at http://www.who.int/reproductivehealth/publications/ maternal_perinatal_heal th/cs-statement/en/.

2. Lumbiganon P, Laopaiboon M, Gulmezoglu AM, Souza JP, Taneepanichskul S, Ruyan P, et al. Method of delivery and pregnancy outcomes in Asia: the WHO global survey on maternal and perinatal health 2007-08. Lancet.2010;375(9713):490-9.

3. Marshall NE, Fu R, Guise JM. Impact of multiple cesarean deliveries on maternal morbidity: a systematic review. Am J Obstet Gynecol. 2011;205(3):262.e1-8.

4. Souza JP, Gülmezoglu AM, Lumbiganon P, Laopaiboon M, Carroli G, Fawole B, et al. Caesarean section without medical indications is associated with an increased risk of adverse short-term maternal outcomes: the 2004-2008 WHO Global Survey on Maternal Perinatal Health. BMC Med. 2010;8(1):71.

5. FIGO Working Group on Challenges in Care of Mothers and Infants during Labour and Delivery,"Best practise advice on the 10-Group Classification System for caesarean deliveries," Int J Gynecol Obstet. 2016;135(2);232-3.

6. Robson M, Murphy M, Byrne F, Quality Assurance, The 10 group classification system (Robson
Classification), induction of labour and Caesarean delivery. Int J Gynaecol Obstet. 2015;131(S1):S23-7.

7. Uniceforg.1.UNICEF DATA.[Online]. Available at http://data.unicef.org/topic/maternalhealth/deliverycare/.

8. MacDorman MF, Menacker F, Declercq E. Cesarean birth in the United States: epidemiology, trends, and outcomes. ClinPerinatol 2008;35(2):293-307.

9. Vogel JP, Betrán AP, Vindevoghel N, Souza JP, Torloni MR, Zhang J, et al., Use of the robson classification to assess caesarean section trends in 21 countries: a secondary analysis of two WHO multicountry surveys. The Lancet Globel Health, 2015;3(5):e260-70.

10. Stavrou EP, Ford JB, Shand AW, et al. Epidemiology and trends for caesarean section births in New South Wales, Australia: a population- based study. BMC Pregnancy Childbirth 2011;11(1):8.

Cite this article as: Kant A, Mendiratta S.

Classification of cesarean section through Robson criteria: an emerging concept to audit the increasing cesarean section rate. Int J Reprod Contracept Obstet Gynecol 2018;7:4674-7. 